\title{
TITLE
}

\section{ULTRASOUND GUIDED CENTRAL VENOUS CATHETER PLACEMENT IN NEUROSURGERY}

Jee Jian See M.MED, Pirjo H Manninen MD FRCPC, Michael Lukins MBBS, Nkihu Merah MD

Department of Anesthesia

Toronto Western Hospital, University Health Network, University of Toronto

399 Bathurst Street, Toronto, On M5T 2S8

\section{INTRODUCTION}

Central venous catheterization $(\mathrm{CVC})$ is frequently used for major neurosurgical procedures. Ultrasound assisted placement of CVC in the right internal jugular vein (RIJV) has been shown to be superior to the use of surface landmarks ${ }^{1}$. Patients are usually placed in a head-down position with rotation of the neck. These maneuvers may result in increased intracranial pressure and should be avoided in patients with compromised intracranial compliance. The purpose of this study was to determine the effect of $5^{\circ}$ and $15^{\circ}$ head-down tilt on the size of the RIJV and the time taken for successful cannulation with ultrasound guidance.

\section{METHODS}

After IRB approval, 58 consented patients scheduled for major neurosurgical or spine surgery were randomized to have RIJV cannulated at $5^{\circ}$ or $15^{\circ}$ head-down positions. With the patient's head in the neutral position, the cross- sectional area (CSA) of RIJV at the level of the cricoid was measured at $0^{\circ}$, and head-down positions of $5^{\circ}$ and $15^{\circ}$. The time required, number of attempts and any complications were documented. Statistical analysis was performed.

\section{RESULTS}

25 male and 33 female patients were studied; the mean (SD) age was 52 (16.7) yr, weight 73 (17.1) kg and height $166(10) \mathrm{cm}$. The CSA increased significantly when patients were placed from supine to $5^{\circ}$ and $15^{\circ}$ head-down as shown in the table. However, no statistical difference was observed in the CSA between $5^{\circ}$ and $15^{\circ}$. There were no complications.

\begin{tabular}{|l|l|l|l|}
\hline & Supine $\left(0^{\circ}\right)$ & $5^{\circ}$ head-down & $15^{\circ}$ head-down \\
\hline Mean CSA (SD) of RIJV $\left[\mathrm{cm}^{2}\right]$ & $1.37(0.59)$ & $1.66(0.77)$ & $1.75(0.79)$ \\
\hline $\begin{array}{l}\text { Mean time (SD) taken to successful } \\
\text { cannulation [sec] }\end{array}$ & & $66(56.7)$ & $65(54.9)$ \\
\hline
\end{tabular}

\section{DISCUSSION}

The increase in the cross sectional area of the RIJV when the patients were placed in the head-down tilt was consistent with earlier studies ${ }^{2}$. There is no difference in the CSA and time to successful cannulation of the RIJV between placing subjects at $5^{\circ}$ or $15^{\circ}$ head-down tilt. We conclude that for neurosurgical patients, cannulation of the RIJV may be performed with only $5^{\circ}$ head down tilt using the ultrasound probe.

\section{REFERENCES}

1. BMJ. 16; 327(7411): 361

2. Br J Anaesth. 89(5):769-71 